Article

\title{
Design and Application of Simulating Cutting Experiment System for Drum Shearer
}

\author{
Tianhao Peng *, Changpeng Li $\odot$ and Yanmin Zhu \\ School of Mechanical Engineering, Anhui University of Science and Technology, Huainan 232001, China; \\ cpli@aust.edu.cn (C.L.); ymzhu@aust.edu.cn (Y.Z.) \\ * Correspondence: thpeng@aust.edu.cn; Tel.: +86-181-1951-3026
}

check for

updates

Citation: Peng, T.; Li, C.; Zhu, Y. Design and Application of Simulating Cutting Experiment System for Drum Shearer. Appl. Sci. 2021, 11, 5917. https://doi.org/10.3390/app11135917

Academic Editor: Yosoon Choi

Received: 22 May 2021

Accepted: 23 June 2021

Published: 25 June 2021

Publisher's Note: MDPI stays neutral with regard to jurisdictional claims in published maps and institutional affiliations.

Copyright: (C) 2021 by the authors. Licensee MDPI, Basel, Switzerland. This article is an open access article distributed under the terms and conditions of the Creative Commons Attribution (CC BY) license (https:// creativecommons.org/licenses/by/ $4.0 /)$.

\begin{abstract}
When the shearer cuts coal or rock with different hardness, it will produce corresponding cutting state information. This paper develops a simulation cutting experiment system for the drum shearer based on similarity theory. It took the spiral cutting drum of a shearer as the research target and derived the principal similarity coefficients through the dimensional analysis method. Meanwhile, this paper designed the structure of the cutting power system and hydraulic system. Then, it chose a certain amount of coal powder as an aggregate, cement 325\# as cementing material, sand, and water as auxiliary materials to prepare simulated coal samples. The paper adopted the orthogonal experiment method and used a proportion of cement, sand, and water as the influencing factors in designing a simulated coal sample preparation plan. In addition, it utilized the range analysis method to research the influence of various factors on the density and compressive strength of simulated coal samples. Finally, it conducted simulated coal sample cutting tests. The results show that the density of the simulated coal samples is between $1192.59 \mathrm{Kg} / \mathrm{m}^{3}-1483.51 \mathrm{Kg} / \mathrm{m}^{3}$, and the compressive strength range reaches $0.16 \mathrm{MPa}-3.94 \mathrm{MPa}$. The density of the simulated coal sample is related to the mass proportion of cement and sand. When the ratio gradually increases, the influence of sand increases. Furthermore, the compressive strength is linearly proportional to the proportion of cement. The self-designed simulation cutting experiment system could effectively carry out the relevant experiments and obtain the corresponding cutting condition signals through the sensors. There are differences in vibration signals generated by cutting different strength materials. Extracting the kurtosis value as the characteristic value can distinguish various cutting modes, which can provide a reliable experimental solution for the research of coal-rock identification.
\end{abstract}

Keywords: shearer; similarity theory; test system; simulated coal sample; orthogonal test

\section{Introduction}

In recent years, China has made remarkable progress in researching and developing coal-mining equipment and fully mechanized mining technology. It has extensively advanced the coal industry in the direction of intelligence and fluidization [1,2]. As one of the vital equipment of fully mechanized mining face, the shearer has realized the efficient and intensive coal-mining operation, which has reduced the incidence of coal mine safety accidents and improved the working environment of coal miners [3-5]. The success of the intelligent control of the shearer determines the possibility of automatic operation of the fully mechanized mining face, to a certain extent. For this, coal and rock recognition technology has received extensive research and attention [6]. Most of the existing coal and rock identification technologies use the working condition signals generated when the shearer cuts different coal and rock media for identification and determination. Therefore, when conducting relevant experimental research, the similarity and reliability of the shearer cutting experimental system must meet certain requirements to generate meaningful results.

Researchers' methods to carry out experimental research on coal and rock identification mainly include (1) Field experiments. By arranging sensors and other measuring 
devices on the coal-mining face, they could collect the working condition signals of the coal and rock for analysis and judgment [7]. (2) Ground experiment. Use a real coalmining machine to conduct actual coal and rock cutting experiments on the ground and obtain various performance data [8]. (3) Single drum cutting experiment. Scholars designed and manufactured a single cutting drum to simulate the cutting experiments of coal and rock [9].

Signal acquisition on the coal-mining face can ensure the authenticity of signal acquisition, but it faces high-risk and harsh working environment constraints. At the same time, the signal acquisition device also needs to meet explosion-proof requirements, and the experimental risk is relatively high. A ground experiment requires supporting coal-mining machines, actual coal, rock medium, and related equipment, and the test cost is relatively high. The single drum cutting experiment is a cost-effective simulation experiment method. However, the system's reliability needs to be discussed.

The geomechanics model experiment can analyze and explore the multi-source information generated in the coal-mining process and is an effective method for studying coal and rock identification. To accurately simulate the working state of the shearer during cutting, the experimental device and simulation material established by using similarity theory need to be like the prototype. At present, there is still a lack of complete and systematic research on coal and rock identification experiments. Thus, based on the existing research and the similarity theory, this paper describes the design and constructing a simulation cutting experimental system of drum shearer to acquire performance data to meet this gap. At the same time, combined with the orthogonal experiment method, the influence of the different material ratio schemes on the performance of simulated cutting material was studied. Finally, some cutting experiments are summarized.

\section{Simulating Spiral Drum}

\subsection{Introduction to Similarity Theory}

The similarity theory is the basis of the research on the experimental system of the drum shearer simulating cutting. It bases on three theorems.

(1) The first theorem of similarity.

For the known similar phenomena, the value of the similarity criterion is the same;

(2) The second theorem of similarity.

Assuming that a specific model system contains $\mathrm{m}$ parameters and $\mathrm{k}$ mutually independent dimensions, then these $\mathrm{m}$ parameters can be transformed into a relationship consisting of similarity criteria $\pi_{1}, \pi_{2}, \ldots, \pi_{n-k}$ :

$$
f\left(\pi_{1}, \pi_{2}, \ldots \pi_{n-k}\right)=0
$$

The second theorem of similarity is also called the $\pi$ theorem. It provides a theoretical basis for simulation experiments. According to the theorem, it can calculate the similarity criterion relationship between the model and the prototype;

(3) The third theorem of similarity.

For a system, if a single parameter is similar, then the similarity criterion composed of it is equal in value. Meanwhile, the system is similar. This theorem is a necessary and sufficient condition for constructing a simulated cutting experimental system.

\subsection{Design of the Spiral Drum}

The spiral drum is the cutting device in the cutting process of the shearer, and its practical simulation design is the key to ensuring the similarity between the experimental device and the prototype [10]. This paper takes the drum structure of the shearer as the primary research object and chooses a thin shearer as the prototype. It uses MLT dimensional analysis and similarity criterion derivation to study the cutting mechanism 
and related movement and structural parameters of the drum during operation [11]. When analyzing, consider the following parameters:

Drum geometric structure parameters. Drum diameter $D$. Blade outer edge diameter $D_{y}$. Drum hub diameter $D_{g}$. Drum cut depth $B$. Spiral blade lift angle $\alpha$. Blade lead $H$. Blade head number $Z$. Blade pitch $S$. Blade hub wrap angle $\beta$. Pick pitch $T$. Pick installation angle $\gamma$. Pick inclination angle $\lambda$.

Material parameters. According to coal and rock identification requirements, the primary consideration is to simulate the compressive strength $\sigma_{y}$ and material density $\rho$ of coal and rock materials.

Operation parameters. Swing angle range $\theta$ of the rocker arm, cutting resistance $F$, cutting power $P$, rotating speed of drum $n$, traction speed $v$.

The above parameters will be able to obtain the parameter dimension matrix of the spiral drum, as shown in Table 1.

Table 1. Dimensional matrix of spiral drum design parameters.

\begin{tabular}{ccccccccccccccccccccccccc}
\hline Parameters & $\boldsymbol{D}$ & $\boldsymbol{D}_{\boldsymbol{y}}$ & $\boldsymbol{D}_{\boldsymbol{g}}$ & $\boldsymbol{B}$ & $\boldsymbol{\alpha}$ & $\boldsymbol{H}$ & $\boldsymbol{Z}$ & $\boldsymbol{S}$ & $\boldsymbol{\beta}$ & $\boldsymbol{T}$ & $\boldsymbol{\gamma}$ & $\boldsymbol{\lambda}$ & $\sigma_{\boldsymbol{y}}$ & $\boldsymbol{\rho}$ & $\boldsymbol{g}$ & $\boldsymbol{\theta}$ & $\boldsymbol{F}$ & $\boldsymbol{P}$ & $\boldsymbol{n}$ & $\boldsymbol{v}$ \\
\hline Index & $a_{1}$ & $a_{2}$ & $a_{3}$ & $a_{4}$ & $a_{5}$ & $a_{6}$ & $a_{7}$ & $a_{8}$ & $a_{9}$ & $a_{10}$ & $a_{11}$ & $a_{12}$ & $a_{13}$ & $a_{14}$ & $a_{15}$ & $a_{16}$ & $a_{17}$ & $a_{18}$ & $a_{19}$ & $a_{20}$ \\
$M$ & 0 & 0 & 0 & 0 & 0 & 0 & 0 & 0 & 0 & 0 & 0 & 0 & 1 & 1 & 0 & 0 & 1 & 1 & 0 & 0 \\
$L$ & 1 & 1 & 1 & 1 & 0 & 1 & 0 & 1 & 0 & 1 & 0 & 0 & -1 & -3 & 1 & 0 & 1 & 2 & 0 & 1 \\
$T$ & 0 & 0 & 0 & 0 & 0 & 0 & 0 & 0 & 0 & 0 & 0 & 0 & -2 & 0 & -2 & 0 & -2 & -3 & -1 & -1 \\
\hline
\end{tabular}

On the basis of the second similarity theorem, this paper determined that the number of similarity criteria by the total number of physical quantities and the rank of the dimension matrix. The similarity criterion equation of the system is as follows:

$$
f\left(D, D_{y}, D_{g}, B, \alpha, H, Z, S, \beta, T, \gamma, \lambda, \sigma_{y}, \rho, g, \theta, F, P, n, v\right)=0
$$

There is a total of 20 system parameters. After subtracting the rank 3 of the matrix, the number of similarity criteria is 17. Because it contains 6 dimensionless quantities, it can be regarded as an independent $\pi$ term. Therefore, the number of similarity criteria to be calculated is 11 . Use the exponential method to analyze the dimensions of the system and obtain the linear homogeneous equations of the quality system.

$$
\left\{\begin{array}{l}
M: a_{13}+a_{14}+a_{17}+a_{18}=0 \\
L: a_{1}+a_{2}+a_{3}+a_{4}+a_{6}+a_{8}+a_{10}-a_{13}-3 a_{14}+a_{15}+a_{17}+2 a_{18}+a_{20}=0 \\
T:-2 a_{13}-2 a_{15}-2_{17}-3 a_{18}-a_{19}-a_{20}=0
\end{array}\right.
$$

The similarity criterion for calculating different dimension parameters is:

$$
\left\{\begin{array}{l}
\pi_{1}=D n / v, \pi_{2}=D_{y} n / v, \pi_{3}=D_{g} n / v, \pi_{4}=B n / v, \pi_{6}=H n / v, \pi_{8}=S n / v \\
\pi_{10}=T n / v, \pi_{13}=\sigma_{y} v^{3} /\left(P n^{2}\right), \pi_{14}=\rho v^{5} /\left(P n^{2}\right), \pi_{15}=g /(n v), \pi_{17}=F v / P \\
\pi_{5}=\alpha, \pi_{7}=Z, \pi_{9}=\beta, \pi_{11}=\gamma, \pi_{12}=\lambda, \pi_{16}=\theta
\end{array}\right.
$$

The $\pi$ term is an invariant, and the similarity index is one according to the first similarity theorem. The similarity coefficient expression is as follows:

$$
\left\{\begin{array}{l}
\frac{C_{D} C_{n}}{C_{v}}=1, \frac{C_{D_{y}} C_{n}}{C_{v}}=1, \frac{C_{D_{g}} C_{n}}{C_{v}}=1, \frac{C_{B} C_{n}}{C_{v}}=1, \frac{C_{H} C_{n}}{C_{v}}=1, \frac{C_{S} C_{n}}{C_{v}}=1, \frac{C_{T} C_{n}}{C_{v}}=1 \\
\frac{C_{\sigma_{y}} C_{v}^{3}}{C_{P} C_{n}^{2}}=1, \frac{C_{\rho} C_{v}^{5}}{C_{P} C_{n}^{2}}=1, \frac{C_{g}}{C_{n} C_{v}}=1, \frac{C_{F} C_{v}}{C_{P}}=1, C_{\alpha}=1, C_{Z}=1, C_{\beta}=1, C_{\gamma}=1, C_{\lambda}=1
\end{array}\right.
$$

Considering the actual design of the simulated shearer, set the similarity coefficient of the drum diameter $D$ to $1 / 4$. The simulated cutting material is made of pulverized coal according to the similar principle, and the similarity coefficient of the material density is set to $1[12,13]$. At the same time, the gravitational acceleration $g$ value remains unchanged. 
Based on this, the similarity coefficients of the main parameters of the shearer simulating coal and rock cutting system are shown in Table 2.

Table 2. Similarity coefficients of the simulated shearer cutting system.

\begin{tabular}{|c|c|c|c|c|c|}
\hline Parameters & Model & Prototype & Parameters & Mode & Prototype \\
\hline Drum diameter $(\mathrm{mm})$ & $D / 4$ & $D$ & Pick installation angle $\left(^{\circ}\right)$ & $\gamma$ & $\gamma$ \\
\hline Blade outer edge diameter ( $\mathrm{mm}$ ) & $D_{y} / 4$ & $D_{y}$ & Pick inclination angle $\left(^{\circ}\right)$ & $\lambda$ & $\lambda$ \\
\hline Drum hub diameter $(\mathrm{mm})$ & $D_{g} / 4$ & $D_{g}$ & Compressive strength $(\mathrm{Pa})$ & $\sigma_{y} / 4$ & $\sigma_{y}$ \\
\hline Drum cut depth (mm) & $B / 4$ & $B^{\circ}$ & Density $\left(\mathrm{Kg} / \mathrm{m}^{3}\right)$ & $\rho$ & $\rho_{m}$ \\
\hline Spiral blade lift angle $\left(^{\circ}\right)$ & $\alpha$ & $\alpha$ & Acceleration of gravity $\left(\mathrm{m} / \mathrm{s}^{2}\right)$ & $g$ & $g$ \\
\hline Blade lead $(\mathrm{mm})$ & $H / 4$ & $H$ & Swing angle range of rock $\operatorname{arm}\left({ }^{\circ}\right)$ & $\theta$ & $\theta$ \\
\hline Blade head number & Z & $Z$ & Cutting resistance $(\mathrm{N})$ & $F / 64$ & $F$ \\
\hline Blade pitch $(\mathrm{mm})$ & $S / 4$ & $S$ & Cutting power $(\mathrm{kW})$ & $P / 128$ & $P$ \\
\hline Blade hub wrap angle $\left(^{\circ}\right)$ & $\beta$ & $\beta$ & Rotating speed of drum (r/min) & $2 n$ & $n$ \\
\hline Pick pitch $(\mathrm{mm})$ & $T / 4$ & $T$ & Traction speed $(\mathrm{m} / \mathrm{min})$ & $v / 2$ & $v$ \\
\hline
\end{tabular}

Based on the structure of the shearer, the cutting drum uses a sequential pick configuration [14]. Establish a three-dimensional model of the cutting drum, as drawn in Figure 1.

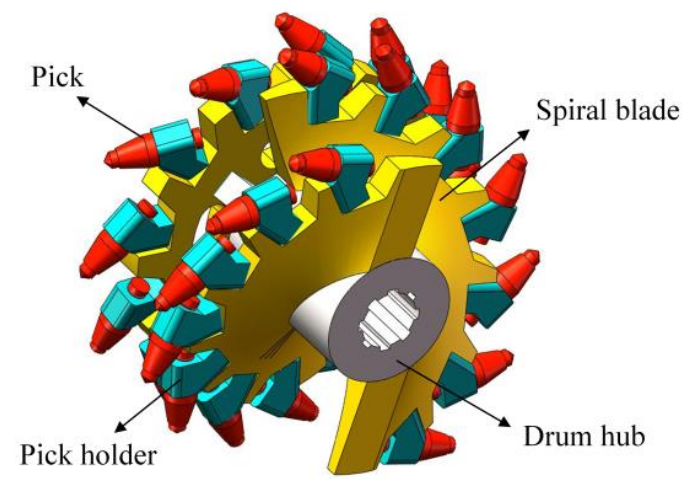

Figure 1. Three-dimensional model of the cutting drum.

\section{Experimental Device Structure}

Following the similarity coefficients in Table 2, combined with the similarity theory, the research developed a simulated shearer cutting experiment device.

As described in Figure 2, it is the cutting power system of the simulated shearer experimental cutting device. The cutting motor is connected to the gear reducer through coupling to realize the speed control of the cutting drum for cutting work [15].

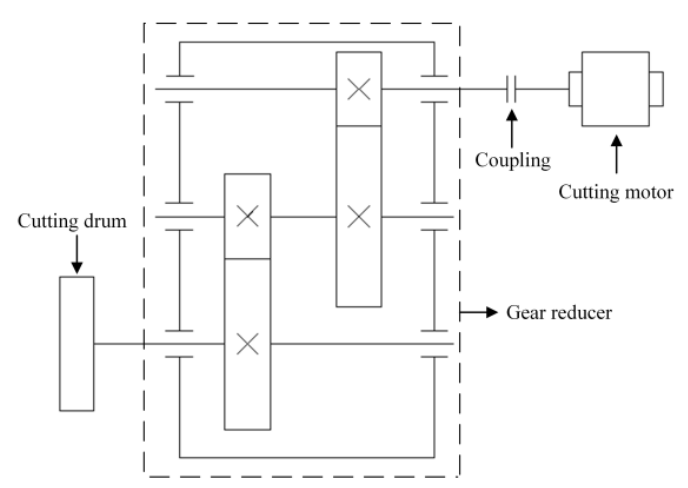

Figure 2. Schematic diagram of the cutting power system. 
The traditional shearer hydraulic system primarily uses the combination of quantitative pump and directional valve, which is difficult to ensure the accurate control of the drum structure in the cutting process [16].

Therefore, the simulation experiment system primarily adopts the hydraulic system controlled by an electro-hydraulic proportional directional valve. The system's required functions divided the hydraulic system into traction circuit, height adjustment circuit, manual circuit, and high-pressure oil source circuit. The hydraulic traction circuit drives the experimental device for linear motion. Meanwhile, the hydraulic height adjustment circuit controls the height adjustment of the drum. In addition, the manual circuit performs as an auxiliary structure. Finally, the supply of high-pressure oil in the entire hydraulic system relies on the high-pressure oil source hydraulic circuit. The schematic diagram of establishing the hydraulic system of the simulated shearer is shown in Figure 3.

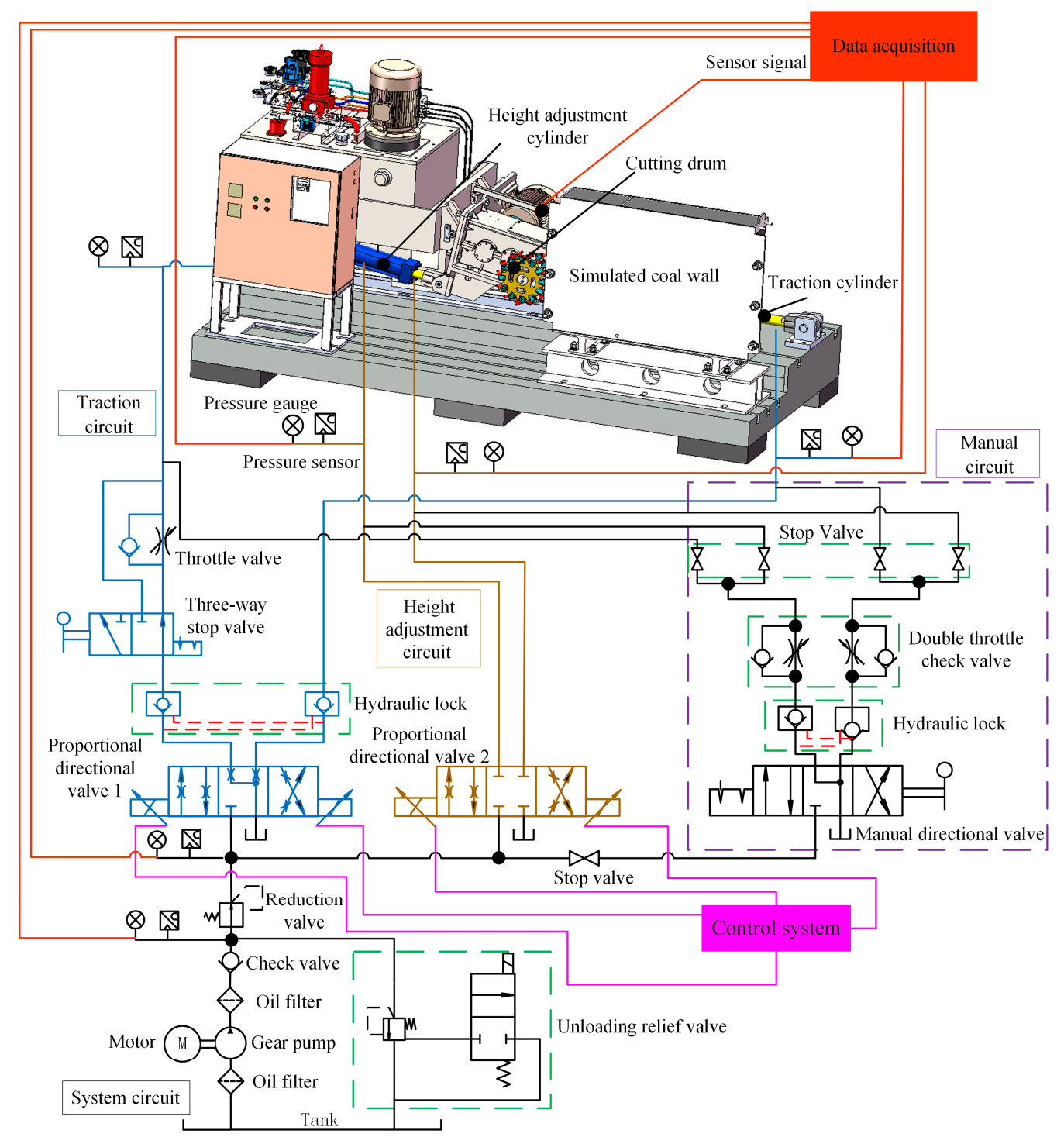

Figure 3. Schematic diagram of the hydraulic system.

\section{Preparation of Simulated Coal Sample}

In order to carry out experimental research accurately, the characteristics of the simulated cutting material and natural coal and rock materials need to meet similar theories. Based on the characteristics of the cutting medium, it obtains the simulated cutting material by controlling the parameter ratio of different materials. Because of the actual working conditions of the shearer and the need to guarantee the working life of the experimental 
device, this paper replaced the rock with a simulated coal sample of higher hardness. Meanwhile, for ensuring the reliability of the simulation experiment results, the simulated coal sample material should ensure a certain uniformity. Unlike the artificially simulated coal sample material, there are several problems, such as bedding, joints, and cracks in the actual coal seam [17]. Existing research results show that, compared to natural coal samples, the compressive strength of simulated coal samples is about 2.5 times that of natural coal samples [18]. Therefore, the strength coefficient of the simulated coal sample is $1 / 2.5$. Combined with the similarity criterion, establish the formula for calculating the unidirectional compressive strength of the cutting material of the simulated coal sample as follows:

$$
\sigma_{y m}=\sigma_{y} C_{\sigma_{y}} \mu
$$

where $\sigma_{y m}$ is the compressive strength of the simulated coal sample material, $\sigma_{y}$ means the compressive strength of the natural coal sample material, $C_{\sigma_{y}}$ represents the similarity coefficient of the simulated cutting material, and $\mu$ expresses the strength coefficient.

According to Formula (6), the compressive strength of the simulated coal sample is about $1 / 10$ of that of the natural coal sample.

\subsection{Selection of Simulated Similar Materials}

As a brittle material, natural coal samples have compressive strength within a specific range [19]. Similar materials of simulated coal samples mainly include aggregates, cements, and auxiliary materials [20]. Combining with the Similarity criteria, select coal powder from a mine in Huainan (one of China's major coal mining regions) as an aggregate to prepare simulated coal samples. Use a 20 mesh sieve for screening before preparation. Add ordinary 325\# Portland cement as the cementing material. It realizes the adjustment of the compressive strength of the simulated coal sample by regulating the cement ratio. In order to get closer to the actual coal sample, sand with the same particle size as the coal powder and ordinary tap water is selected as auxiliary materials.

\subsection{Preparation of Simulated Coal Sample}

In order to prepare a simulated coal sample material that meets the requirements of the experiment, this paper uses an orthogonal experiment method to design a ratio scheme. The influencing factors of the experiment are the mass ratio of cement, sand, and water. There are five levels for each factor. Choose the $\mathrm{L}_{25}\left(5^{6}\right)$ experimental program. The orthogonal experiment method regards columns 1,2, and 6 as influencing factor columns and uses the remaining empty columns for error analysis. Combined with the results of the previous experiments, the level of similar material factors to determine the simulated coal sample is listed in Table 3.

Table 3. Factor levels of similar materials.

\begin{tabular}{cccc}
\hline \multirow{2}{*}{ Level } & & Mass Ratio/\% & \\
\cline { 2 - 4 } & Cement & Sand & Water \\
\hline 1 & 5 & 5 & 10 \\
2 & 10 & 10 & 11 \\
3 & 15 & 15 & 12 \\
4 & 20 & 20 & 13 \\
5 & 25 & 25 & 14 \\
\hline
\end{tabular}

This study prepared three sets of simulated coal samples for each experimental program. The size of each group of test pieces is $\$ 50 \mathrm{~mm} \times 100 \mathrm{~mm}$, and the preparation process is as follows:

(1) According to requirements, select the coal powder and sand that meet the production conditions; 
(2) Weigh coal, cement, sand, and water according to the experimental plan, mix them thoroughly, and stir them evenly;

(3) Put the mixed material into the forming mold and compact it;

(4) Label and strip the test piece, and maintain it for 14 days at room temperature.

The simulated coal sample preparation is presented in Figure 4.

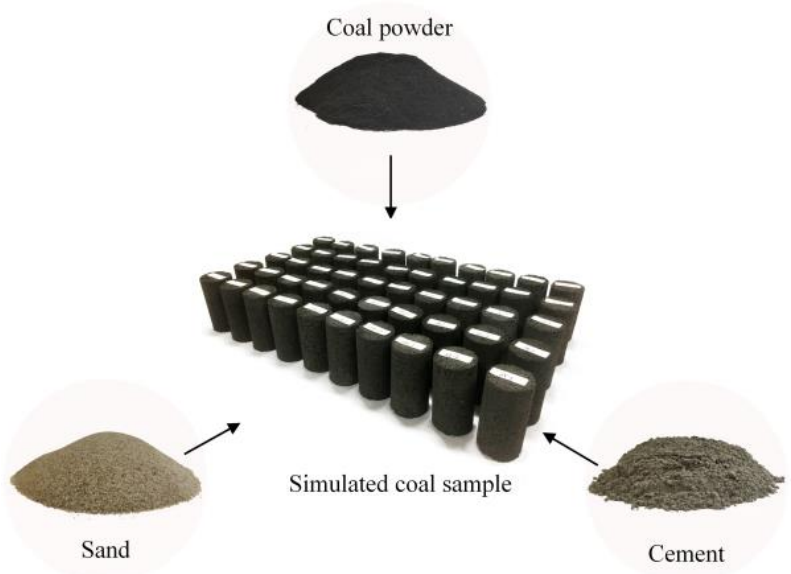

Figure 4. Preparation of simulated coal sample.

\section{Analysis of Orthogonal Experiment Results}

After the simulated coal sample is prepared and cured, it is measured and weighed with a vernier caliper and an electronic balance to calculate the density of the material. The paper uses a $20 \mathrm{KN}$ microcomputer-controlled electronic universal testing machine for uniaxial compressive strength testing. Set the loading rate in the displacement control mode to $1 \mathrm{~mm}$ per minute. As reflected in Figure 5, as the load applied by the testing machine gradually increases, until failure occurs, the compression test ends.

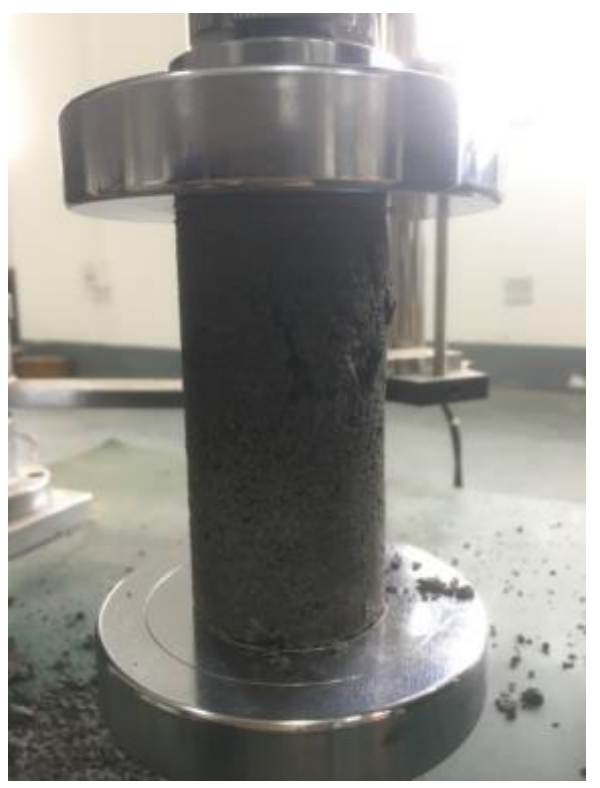

Figure 5. Fragmentation diagram of simulated coal sample.

It has taken the second group of samples in experimental plan 13 as an example, the stress-strain curve of the simulated coal sample is shown in Figure 6. The maximum uniaxial compressive strength of the simulated coal sample reached $2.12 \mathrm{MPa}$, and the simulated coal sample suffered a sliding shear failure [21,22]. Figures 5 and 6 show that 
the failure mode of the simulated coal sample is the same as that of the natural coal sample. The test reflects the similarity between the prepared simulated coal sample and the natural coal sample. Compression experiments were performed on all simulated coal samples, and the average value of the calculated experimental results is listed in Table 4.

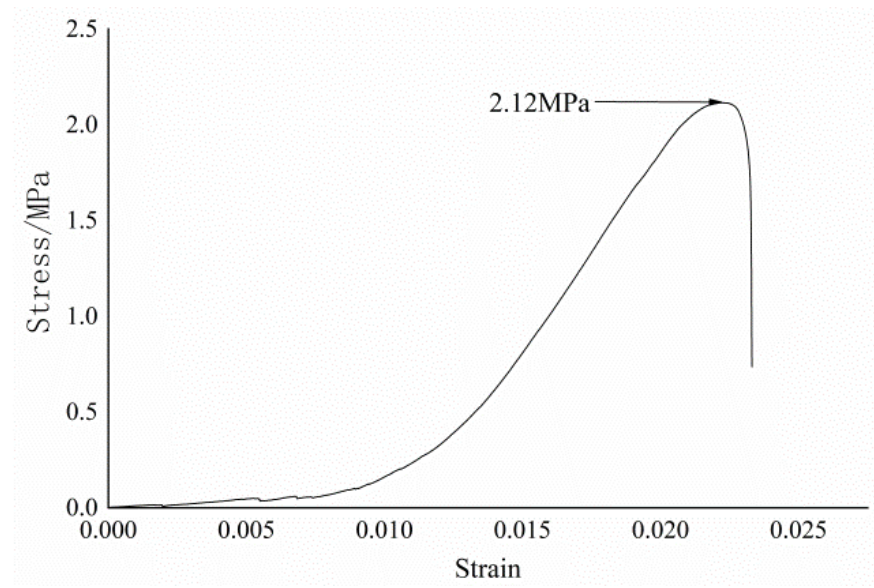

Figure 6. Stress-strain curve of simulated coal sample.

Table 4. Orthogonal test results of simulated coal samples.

\begin{tabular}{|c|c|c|c|c|c|c|}
\hline \multirow{2}{*}{ Experimental Plan } & \multicolumn{4}{|c|}{ Proportion of Similar Material Quality/\% } & \multirow{2}{*}{ Mass Density $\left(\mathrm{kg} / \mathrm{m}^{3}\right)$} & \multirow{2}{*}{ Compressive Strength (MPa) } \\
\hline & Cement & Sand & Water & Coal Powder & & \\
\hline 1 & 5 & 5 & 10 & 80 & 1192.59 & 0.16 \\
\hline 2 & 5 & 10 & 11 & 74 & 1223.69 & 0.23 \\
\hline 3 & 5 & 15 & 12 & 68 & 1263.47 & 0.23 \\
\hline 4 & 5 & 20 & 13 & 62 & 1308.98 & 0.24 \\
\hline 5 & 5 & 25 & 14 & 56 & 1336.73 & 0.17 \\
\hline 6 & 10 & 5 & 14 & 71 & 1309.01 & 0.89 \\
\hline 7 & 10 & 10 & 10 & 70 & 1324.32 & 1.03 \\
\hline 8 & 10 & 15 & 11 & 64 & 1331.77 & 1.10 \\
\hline 9 & 10 & 20 & 12 & 58 & 1345.44 & 1.07 \\
\hline 10 & 10 & 25 & 13 & 52 & 1395.18 & 0.97 \\
\hline 11 & 15 & 5 & 13 & 67 & 1311.72 & 1.85 \\
\hline 12 & 15 & 10 & 14 & 61 & 1362.98 & 2.22 \\
\hline 13 & 15 & 15 & 10 & 60 & 1349.28 & 2.14 \\
\hline 14 & 15 & 20 & 11 & 54 & 1360.95 & 1.74 \\
\hline 15 & 15 & 25 & 12 & 48 & 1483.71 & 2.49 \\
\hline 16 & 20 & 5 & 12 & 63 & 1335.50 & 2.63 \\
\hline 17 & 20 & 10 & 13 & 57 & 1353.75 & 2.67 \\
\hline 18 & 20 & 15 & 14 & 51 & 1378.25 & 2.92 \\
\hline 19 & 20 & 20 & 10 & 50 & 1380.28 & 2.61 \\
\hline 20 & 20 & 25 & 11 & 44 & 1396.82 & 2.30 \\
\hline 21 & 25 & 5 & 11 & 59 & 1253.99 & 1.97 \\
\hline 22 & 25 & 10 & 12 & 53 & 1350.55 & 3.38 \\
\hline 23 & 25 & 15 & 13 & 47 & 1406.54 & 3.94 \\
\hline 24 & 25 & 20 & 14 & 41 & 1444.63 & 3.80 \\
\hline 25 & 25 & 25 & 10 & 40 & 1478.72 & 3.51 \\
\hline
\end{tabular}

Table 4 displays that the density of the simulated coal sample prepared according to the orthogonal experimental scheme is between $1192.59 \mathrm{Kg} / \mathrm{m}^{3}$ and $1483.51 \mathrm{Kg} / \mathrm{m}^{3}$. Therefore, the density of the prepared simulated coal samples is consistent with the density of coal in the Huainan area. In addition, the compressive strength range reaches $0.16 \mathrm{MPa}-3.94 \mathrm{MPa}$. 


\subsection{Density Analysis of Simulated Coal Samples}

For the simulated coal sample density, this paper calculated the range of each influencing factor summarized in Table 5. At the same time, it established a trend chart of influencing factors, as shown in Figure 7.

Table 5. Range analysis for the density of simulated coal samples.

\begin{tabular}{cccc}
\hline Level & Cement & Sand & Water \\
\hline 1 & 1265.09 & 1280.56 & 1345.04 \\
2 & 1341.14 & 1323.06 & 1313.44 \\
3 & 1373.73 & 1345.86 & 1355.73 \\
4 & 1368.92 & 1368.05 & 1355.24 \\
5 & 1386.89 & 1418.23 & 1366.32 \\
Range & 121.79 & 137.67 & 52.88 \\
\hline
\end{tabular}

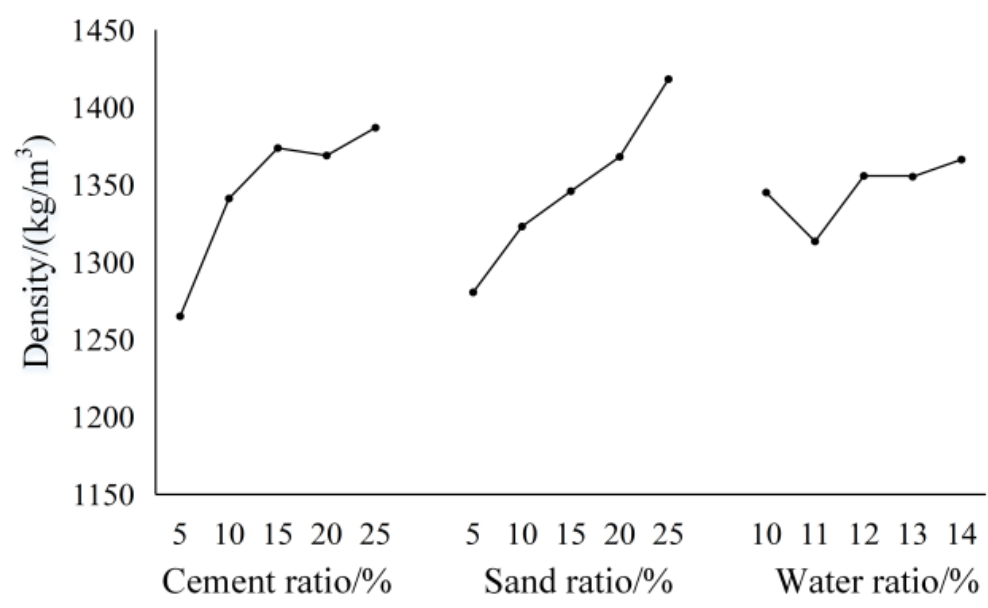

Figure 7. Trend chart of density influencing factors.

The curve in Figure 7 shows that the density of the simulated coal sample rises linearly when the mass ratio of cement is in the range of $5-15 \%$. Then, the density growth rate of the simulated coal sample gradually slowed down. In the range of $5-25 \%$, the promotion of sand mass proportion leads to increased density of simulated coal samples. When the mass ratio of water is $11 \%$, the density of the simulated coal sample has a minimum value, and the fluctuation degree of the curve is low in other ranges.

Table 5 and Figure 7 reflect that both cement and sand can affect the density of the simulated coal sample. In the simulated similar materials, the density of sand and cement is higher than that of coal powder. The range of sand and cement is 121.97 and 137.67, respectively. However, the range of water is 52.88 , which is much smaller than that of cement and sand. The proportion of sand and cement determines the density of the simulated coal sample. Therefore, the influence of the proportion of water is not apparent. Meanwhile, the density of sand is greater than that of cement. As the proportion of mass increases, the effect of cement on the simulated coal samples gradually decreases, and the role of sand becomes significant.

\subsection{Compressive Strength Analysis of Simulated Coal Samples}

Calculate the range of each influencing factor that affects the compressive strength of the simulated coal sample, with test results summarized in Table 6. The range of sand and water is 0.57 and 0.53 , respectively. Meanwhile, the range of cement is 3.11 . It indicates that the range of the cement's mass fraction is much greater than that of the sand and water. Cement has a significant effect on the compressive strength of simulated coal samples. The impact of sand and water is relatively weak. According to Table 6, the trend graph of influencing factors is described in Figure 8. 
Table 6. Range analysis for the uniaxial compressive strength of simulated coal samples.

\begin{tabular}{cccc}
\hline Level & Cement & Sand & Water \\
\hline 1 & 0.21 & 1.50 & 1.89 \\
2 & 1.01 & 1.91 & 1.47 \\
3 & 2.09 & 2.07 & 1.96 \\
4 & 2.63 & 1.89 & 1.93 \\
5 & 3.32 & 1.89 & 2.00 \\
Range & 3.11 & 0.57 & 0.53 \\
\hline
\end{tabular}

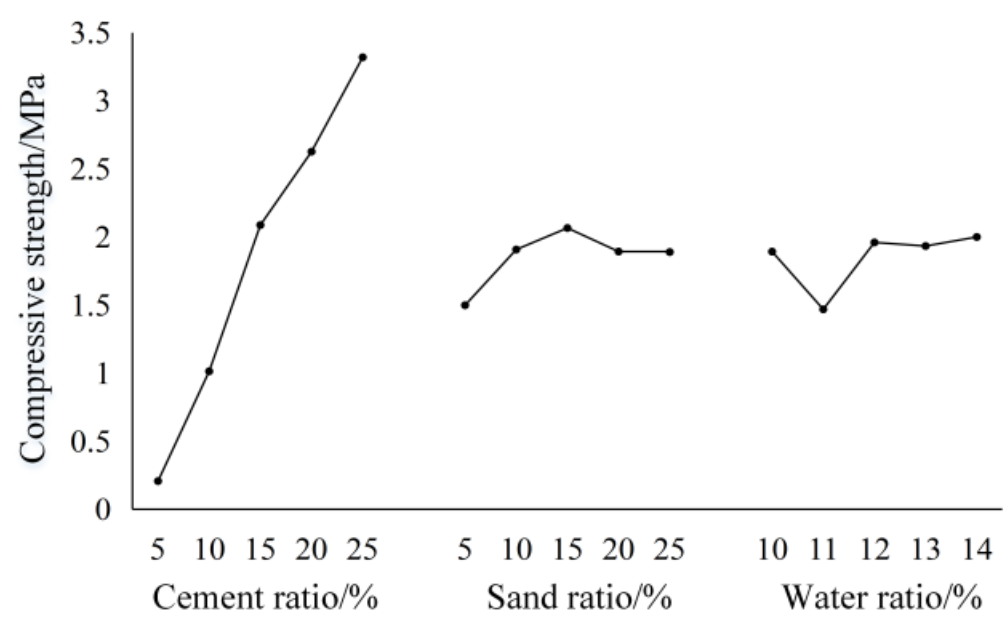

Figure 8. Trend chart of influencing factors of compressive strength.

Figure 8 illustrates that cementing as a cementing agent can affect the compressive strength of simulated coal samples when other conditions remain unchanged. As the proportion of cement increases, the compressive strength of the simulated coal sample gradually increases. The compressive strength first increases and decreases with the mass proportion of sand and reaches the maximum when the ratio reaches $15 \%$. The influencial degree of water is relatively uniform, and there is a minimum value at $11 \%$. Compared with cement, the trend curves of sand and water fluctuate less. It reflects that sand and water have no apparent relationship with the compressive strength of simulated coal samples.

As a result of the test, this paper determines that cement is a significant factor affecting the compressive strength of simulated coal samples and carries out an analysis of variance. In order to quantify the relationship among the three influencing factors and the uniaxial compressive strength of the simulated coal samples, it performs multiple linear regression analysis on the experimental results [23]. The equation is:

$$
Y=-1.8358+15.812 X_{1}+1.368 X_{2}+9.32 X_{3}
$$

where $Y$ is the uniaxial compressive strength of the simulated coal sample, $X_{1}$ is the mass proportion of cement $(5-25 \%), X_{2}$ is the mass proportion of sand (5-25\%), and $X_{3}$ represents the mass proportion of water $(10-14 \%)$.

Set the significance level $\alpha=0.01$, and calculate the multiple correlation coefficient $\mathrm{R}$ of the regression equation to be 0.945 . Check the relevant data and confirm that the critical value of $99 \%$ confidence level $R \min =0.641$ and $R=0.945>0.641$. Therefore, the regression equation is reliable. The experimental data reflect that the equation established has a better fitting effect.

On the basis of the above orthogonal experiment results, this paper determines that the influence of the mass ratio of cement and sand on the density of simulated coal samples is close to a linear relationship. As the mass fraction increases, the sand becomes the primary influence factor. Meanwhile, the compressive strength of the simulated coal sample is most 
significantly affected by the mass proportion of cement. The percentage of water has a weaker impact on density and compressive strength.

\section{Simulated Cutting Experiment}

The laboratory had produced a longwall face with simulated coal with a length $x$ width $\times$ height of $700 \mathrm{~mm} \times 200 \mathrm{~mm} \times 500 \mathrm{~mm}$ according to the experimental plan. The establishment of a simulated cutting experiment system is shown in Figure 9.

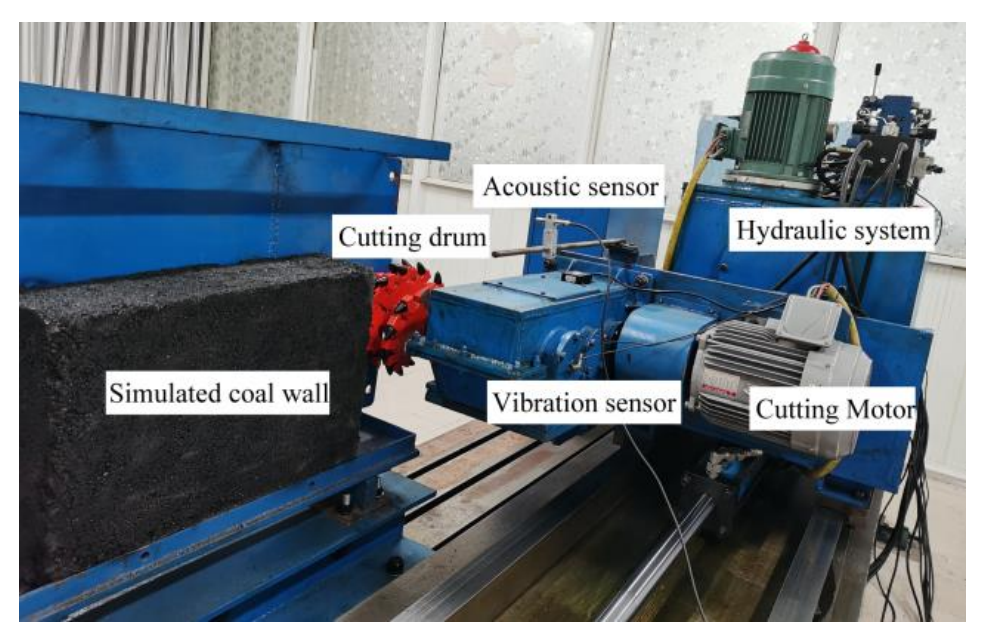

Figure 9. Shearer simulation cutting test system.

When cutting, the cutting motor uses a $30 \mathrm{~Hz}$ input controlled by a frequency converter, and the forward speed of the simulated coal shearer at $0.5 \mathrm{~m}$ per minute, as shown in Figures 9 and 10.

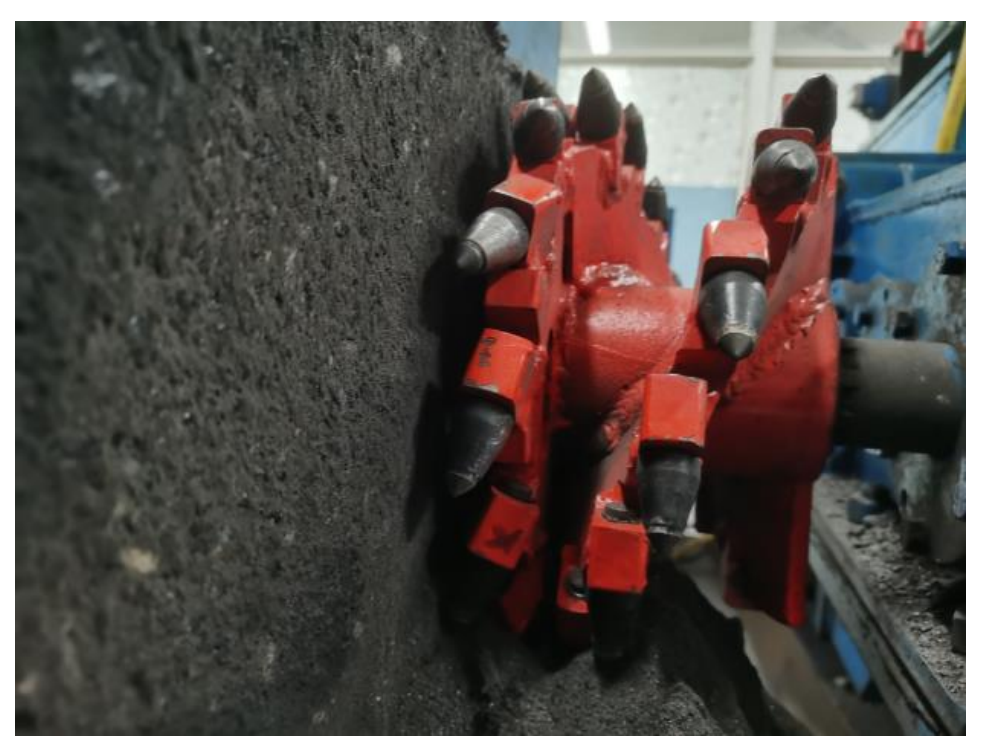

Figure 10. Cutting effect diagram.

Shearer performance and system status data during cutting can be accurately acquired through measuring equipment, such as sound sensors and vibration sensors. For example, vibration signals have been used to interpret cutting conditions. The hardware of the vibration signal acquisition system is listed in Table 7. 
Table 7. List of vibration signal acquisition system.

\begin{tabular}{cc}
\hline Hardware & Model \\
\hline Vibration sensor & LC0109 \\
Data acquisition card & NI PCIe-6323 \\
Terminal plate & CB-68LP \\
\hline
\end{tabular}

When the shearer is cutting, the cutting load generated by the drum when cutting coal walls with various hardness is different. Therefore, it produces different cutting vibration signals. In addition, when the equipment is running, the hydraulic pump station and the cutting motor will produce vibration information [24,25]. Thus, to better collect the vibration signal generated by shearer cutting, the vibration sensor is installed at the end cover of the shaft connected with the drum, as indicated in Figure 11.

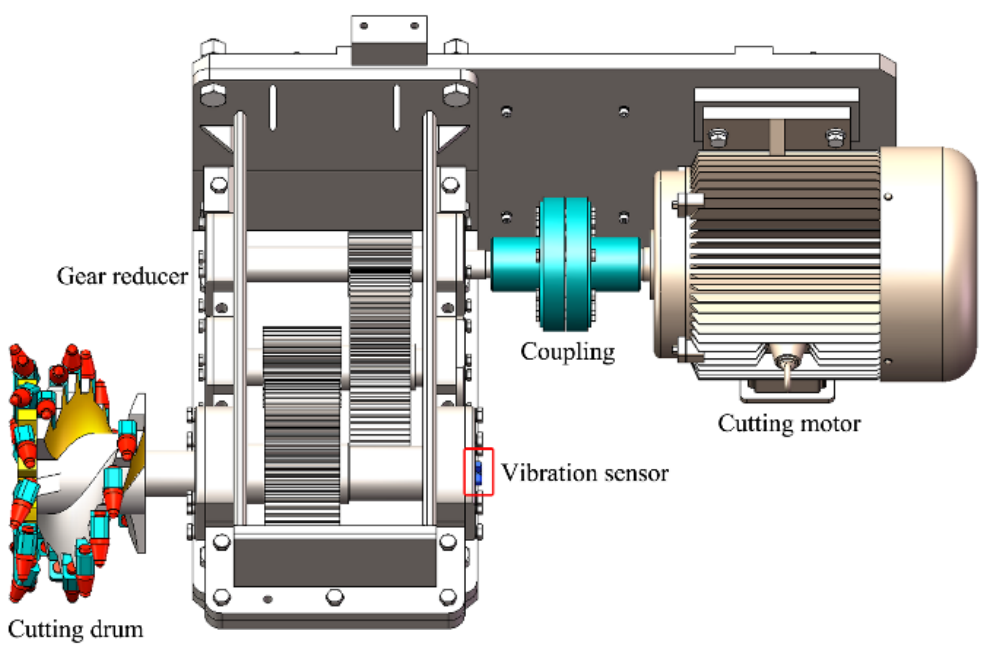

Figure 11. Installation diagram of the vibration sensor.

According to the experimental plans 9, 13, and 18, the study had poured three simulated longwall coal faces and carried out cutting experiments. Meanwhile, it set a no-load cutting mode as the control group. Therefore, the test established four cutting modes, which were denoted as $\mathrm{C} 1, \mathrm{C} 2, \mathrm{C} 3$, and $\mathrm{C} 4$. The various cutting methods correspond, as shown in Table 8.

Table 8. The corresponding situation of cutting mode.

\begin{tabular}{cc}
\hline Cutting Mode & Cutting Medium \\
\hline C1 & No-load \\
C2 & Experimental plan 9 \\
C3 & Experimental plan 13 \\
C4 & Experimental plan 18 \\
\hline
\end{tabular}

When cutting, set the signal sampling frequency of the vibration signal at $48 \mathrm{KHz}$, and the sampling time at $0.1 \mathrm{~s}$. It obtains vibration signals of four cutting modes, as shown in Figure 12. 

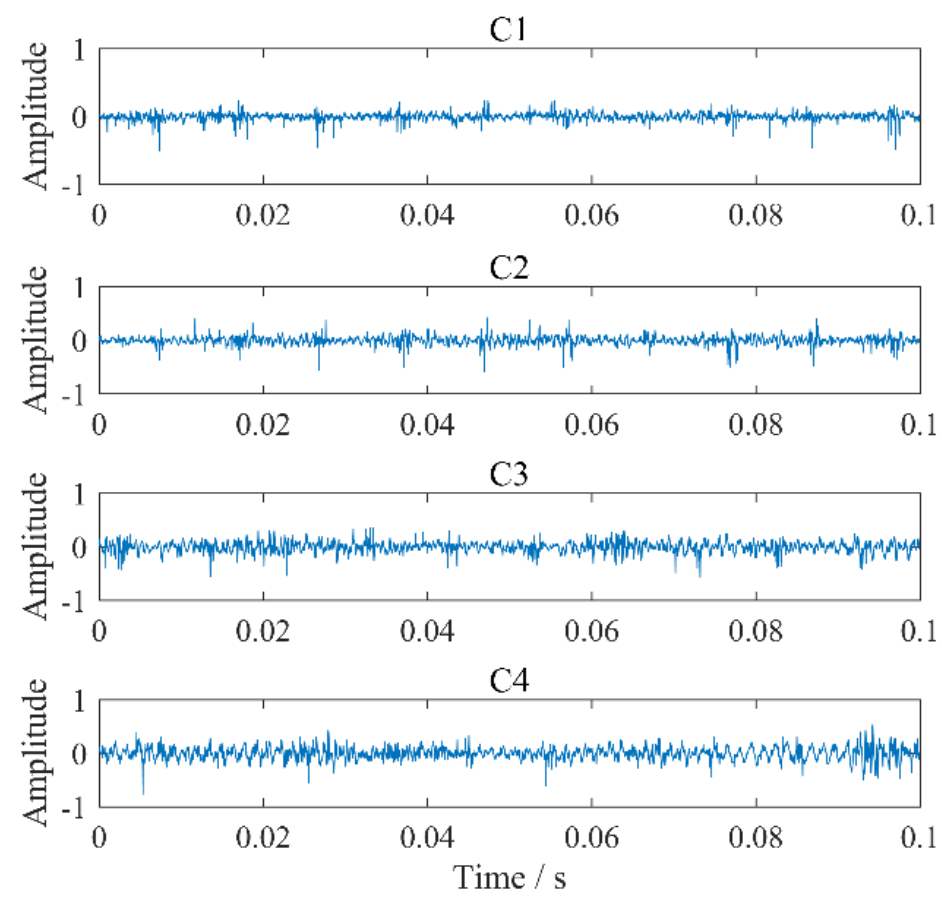

Figure 12. The waveform of cutting vibration signal.

Figure 12 illustrates that the amplitude of the vibration signal in the $\mathrm{C} 1$ no-load cutting mode is relatively minimal. With the increase of cutting medium strength, the vibration signal amplitude of $\mathrm{C} 2, \mathrm{C} 3$, and C4 cutting modes increases gradually. The cutting drum has impact, collision, and friction on the simulated coal wall during operation. There are periodic shock components in the collected cutting vibration signal waveform.

It analyzes the vibration signals of the above four cutting modes in the frequency domain and obtains the spectrum diagram of the vibration signal drawn in Figure 13.
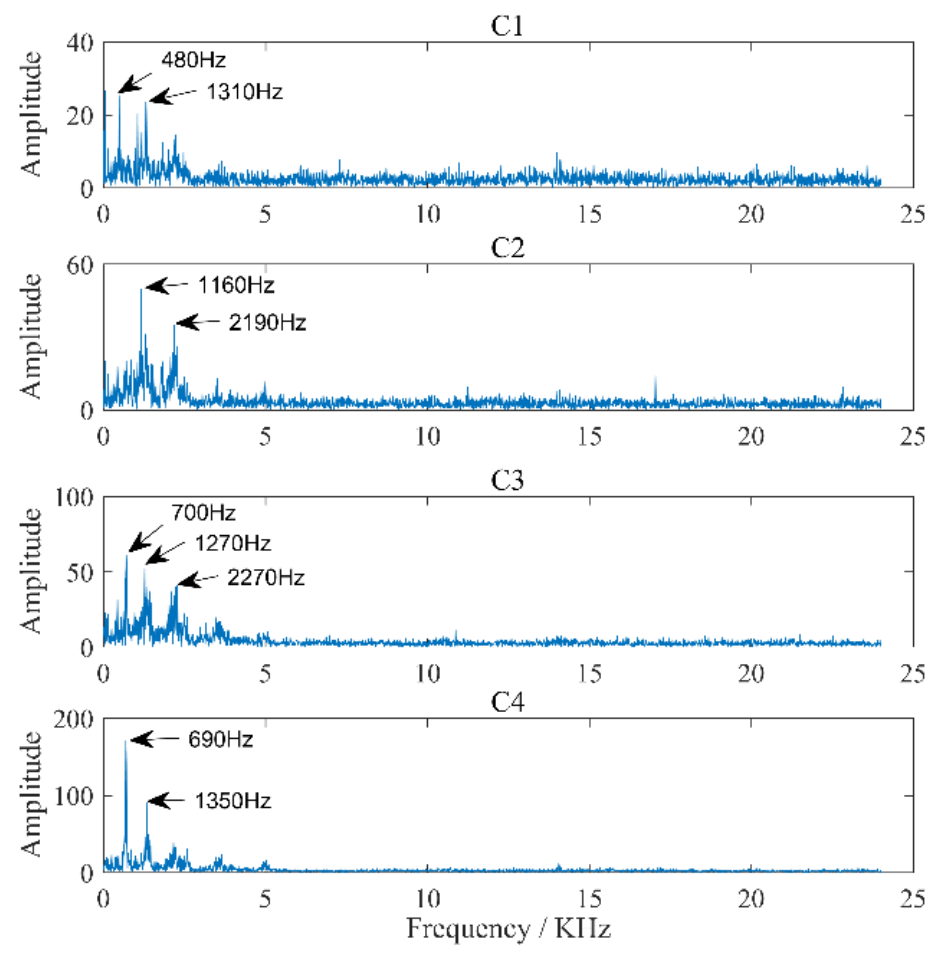

Figure 13. The spectrum of cutting the vibration signal. 
Figure 13 indicates that the energy of the shearer cutting vibration signal is mainly concentrated in the frequency band range of $0 \mathrm{~Hz} 5000 \mathrm{~Hz}$. The vibration signal of the $\mathrm{C} 1$ no-load cutting mode is caused by the hydraulic pump station, cutting motor, and gear reducer. There are mainly two frequency peaks of $480 \mathrm{~Hz}$ and $1310 \mathrm{~Hz}$ in the signal. The C2 cutting mode takes the simulated longwall coal face of the experimental plan 9 as the object, and there are two frequency peaks of $1160 \mathrm{~Hz}$ and $2190 \mathrm{~Hz}$ in the vibration signal collected. Compared with the vibration signal generated by the $\mathrm{C} 1$ no-load cutting mode, the frequency amplitude of the $\mathrm{C} 2$ cutting vibration signal is significantly increased, and the frequency peaks are different. It represents that the vibration generated by the hydraulic pump station, cutting motor, and other vibration sources do not cause apparent interference to the accurate acquisition of the cutting vibration signal. The $\mathrm{C} 3$ cutting mode is based on experimental plan 13. The collected cutting vibration signals have three frequency peaks of $700 \mathrm{~Hz}, 1270 \mathrm{~Hz}$, and $2270 \mathrm{~Hz}$. The frequency amplitude is significantly greater than that of the vibration signal of the $\mathrm{C} 2$ cutting mode. In the $\mathrm{C} 4$ cutting mode, it has been pouring simulated longwall coal face with experimental plan 18 . The collected vibration signals have frequency peaks of $690 \mathrm{~Hz}$ and $1350 \mathrm{~Hz}$, and the frequency amplitude is the largest in the four cutting modes.

Figures 12 and 13 show that the vibration signals of the four cutting modes are different in the time domain and frequency domain. In order to quantify the difference between vibration signals of four cutting modes, signal kurtosis is introduced as an index to evaluate.

Kurtosis is a dimensionless parameter sensitive to vibration shock signal, reflecting the signal's random distribution characteristics. The kurtosis value $K$ can be described as:

$$
K=\frac{\frac{1}{n} \sum_{i=1}^{n}\left(x_{i}-\bar{x}\right)^{4}}{\sigma^{4}}
$$

where $x_{i}$ is a one-dimensional discrete vibration signal, $n$ is the number of signals, $\bar{x}$ is the average value of signal $x_{i}$, and $\sigma$ is the standard deviation of signal $x_{i}$.

The study collected ten groups of the vibration signals under each cutting mode and calculated the kurtosis value of the signal, as shown in Figure 14.

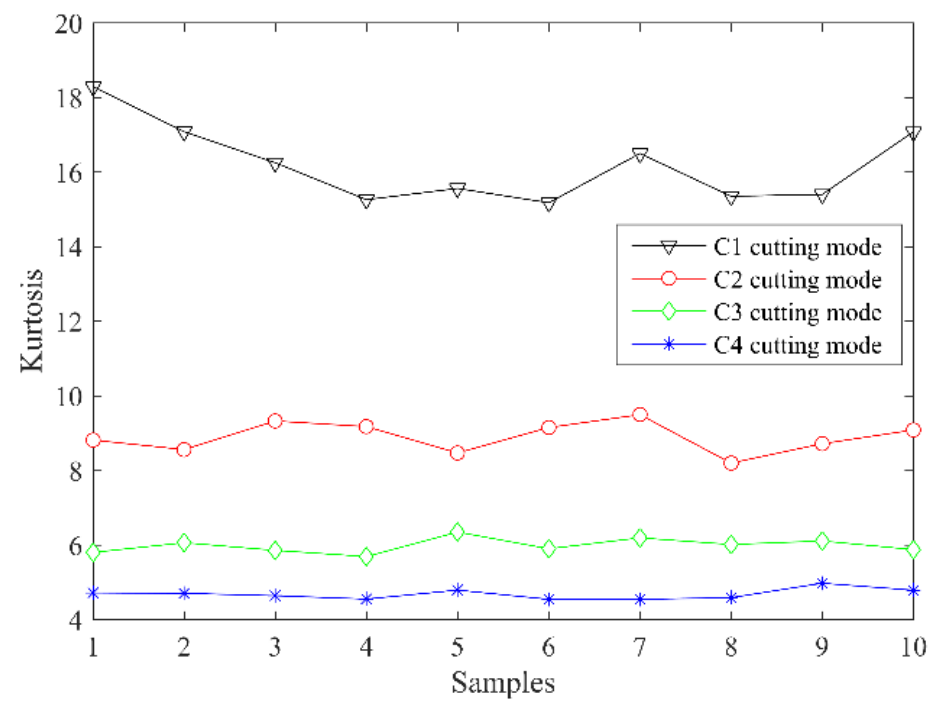

Figure 14. Kurtosis of cutting vibration signal.

Figure 14 shows that there are significant differences in kurtosis values of vibration signals in the four cutting modes. The $\mathrm{C} 1$ cutting mode collects the vibration signal under a no-load state. However, the vibration signals of multiple vibration sources constitute the final collected signal, which has large randomness and high deviation. Hence, it has a considerable kurtosis value. The cutting modes C2, C3, and C4 all cut the simulated 
longwall coal faces, and the collected signals are mainly the cutting vibration signals. Their randomness and dispersion are relatively small. Among the three cutting modes, the simulated longwall coal face hardness of the $\mathrm{C} 2$ cutting mode is smaller, and the interaction force between materials is weak. Thus, the vibration signal generated during cutting is random. Therefore, the kurtosis value of the $\mathrm{C} 2$ cutting mode is relatively large. The simulated coal wall hardness of the $\mathrm{C} 4$ cutting mode is the largest, and the kurtosis value of the vibration signal generated by cutting is the smallest. The kurtosis value of the vibration signal generated by the $\mathrm{C} 3$ cutting mode is between the three modes.

Based on the different proportioning schemes, the system can effectively perform cutting experiments that simulate coal face. By carefully configuring the corresponding sensors on the experimental system, the system can obtain the cutting condition signals required by the coal and rock identification study. Compared with the existing experimental device, the simulated cutting experimental system is safer, more economical, and reliable.

\section{Conclusions}

(1) The study uses a 1:10 strength conversion ratio between the simulated coal sample and the natural coal sample. It chooses coal powder, cement, sand, and water as similar materials to make the simulated coal sample. Then, the research designs the orthogonal experiment and considers the proportion of cement, sand, and water as the influencing factors. Each factor has determined five levels and designed 25 sets of proportioning schemes. The prepared simulated coal samples have to be accurately measured, weighed, and compacted to obtain the density and compressive strength of the simulated coal samples with different ratios;

(2) After careful examination of the influence of different factors on the simulated coal sample's density and uniaxial compressive strength, it was discovered that both cement and sand have an approximate linear effect on the density of simulated coal samples. As the mass percentage increases, the impact of sand increases. Furthermore, the ratio of cement is proportional to the compressive strength;

(3) Finally, this paper prepared several simulated longwall coal face based on the orthogonal experiment results and carried out cutting experiments. The cutting experiment system of a simulated shearer can safely and reliably perform simulated cutting experiments. It can provide an effective and dependable experimental plan for coal and rock identification research and serve as a design guideline for the intelligent cutting of coal mining machines.

Author Contributions: Conceptualization, T.P. and C.L.; methodology, T.P. and C.L.; software, C.L.; validation, T.P., C.L. and Y.Z.; formal analysis, C.L.; resources, T.P.; data curation, C.L.; writingoriginal draft preparation, C.L.; writing-review and editing, T.P.; project administration, T.P.; funding acquisition, T.P. All authors have read and agreed to the published version of the manuscript.

Funding: This research was funded by the National Natural Science Foundation of China (No. 51475001).

Institutional Review Board Statement: Not applicable.

Informed Consent Statement: Not applicable.

Data Availability Statement: The data present in this study are available on request from the corresponding author.

Conflicts of Interest: The authors declare no conflict of interest.

\section{References}

1. Liu, X.; Jing, W.; Zhou, M.; Li, Y. Multi-Scale Feature Fusion for Coal-Rock Recognition Based on Completed Local Binary Pattern and Convolution Neural Network. Entropy 2019, 21, 622. [CrossRef] [PubMed]

2. Zhao, L.; Jin, X.; Liu, X. Numerical research on wear characteristics of drum based on discrete element method (DEM). Eng. Fail. Anal. 2020, 109, 104269. [CrossRef] 
3. Hargrave, C.O.; James, C.A.; Ralston, J.C. Infrastructure-based localisation of automated coal mining equipment. Int. J. Coal Sci. Technol. 2017, 4, 252-261. [CrossRef]

4. Yang, D.-L.; Li, J.-P.; Wang, Y.-X.; Jiang, H.-X. Analysis on vertical steering vibration of drum shearer cutting part. J. Cent. South Univ. 2018, 25, 2722-2732. [CrossRef]

5. Wang, Y.; Liu, C.; Liao, Y. Electromechanical dynamic analysis for the DTC induction motor driving system of the unmanned long-wall shearer drum. Clust. Comput. 2018, 22, 13325-13336. [CrossRef]

6. Si, L.; Wang, Z.; Liu, X.; Tan, C. A sensing identification method for shearer cutting state based on modified multi-scale fuzzy entropy and support vector machine. Eng. Appl. Artif. Intell. 2019, 78, 86-101. [CrossRef]

7. Liu, Y.; Wang, Z.; Si, L.; Zhang, L.; Tan, C.; Xu, J. A Non-Reference Image Denoising Method for Infrared Thermal Image Based on Enhanced Dual-Tree Complex Wavelet Optimized by Fruit Fly Algorithm and Bilateral Filter. Appl. Sci. 2017, 7, 1190. [CrossRef]

8. Si, L.; Wang, Z.-B.; Jiang, G. Fusion Recognition of Shearer Coal-Rock Cutting State Based on Improved RBF Neural Network and D-S Evidence Theory. IEEE Access 2019, 7, 122106-122121. [CrossRef]

9. Wang, H.; Zhang, Q. Dynamic identification of coal-rock interface based on adaptive weight optimization and multi-sensor information fusion. Inf. Fusion 2019, 51, 114-128. [CrossRef]

10. Gao, K.; Xu, W.; Jiang, S.; Du, C. Factors affecting thin coal seam shearer drum coal-loading performance by a model test method. J. Cent. South Univ. 2019, 26, 1619-1636. [CrossRef]

11. Xu, G.; Li, Y.; Deng, H.; Li, H.; Yu, X. The application of similarity theory for heat transfer investigation in rotational internal cooling channel. IJHMT 2015, 85, 98-109. [CrossRef]

12. Yao, Z.; Zhang, P.; Cheng, H.; Xue, W.; Li, X. Testing of a Dual-Steel-Plate-Confined High-Performance Concrete Composite Shaft Lining Structure and Its Application. Appl. Sci. 2020, 10, 2938. [CrossRef]

13. Liu, S.; Du, C.; Cui, X.; Cheng, X. Model test of the cutting properties of a shearer drum. Min. Sci. Technol. (China) 2009, 19, 74-78.

14. Li, X.; Wang, S.; Ge, S.; Malekian, R.; Li, Z.; Li, Y. A study on drum cutting properties with full-scale experiments and numerical simulations. Measurement 2018, 114, 25-36. [CrossRef]

15. Zeng, Q.; Gao, K.; Zhang, H.; Jiang, S.; Jiang, K. Vibration analysis of shearer cutting system using mechanical hydraulic collaboration simulation. Proc. Inst. Mech. Eng. Part K J. Multi-Body Dyn. 2017, 231, 708-725. [CrossRef]

16. Si, L.; Wang, Z.; Liu, X.; Zhang, L. A Novel Compound Control Method for Hydraulically Driven Shearer Drum Lifting. J. Control Sci. Eng. 2014, 2014, 1-12. [CrossRef]

17. Ai, D.; Zhao, Y.; Wang, Q.; Li, C. Crack propagation and dynamic properties of coal under SHPB impact loading: Experimental investigation and numerical simulation. ThAFM 2020, 105, 102393. [CrossRef]

18. Yanning, W.; Yumei, L. Expermient Research on Smiulated Cutting Material. Coal Sci. Technol. (China) 2010, 38, 58-60.

19. Zhao, Y.; Liu, S.; Zhao, G.-F.; Elsworth, D.; Jiang, Y.; Han, J. Failure mechanisms in coal: Dependence on strain rate and microstructure. J. Geophys. Res. Solid Earth 2014, 119, 6924-6935. [CrossRef]

20. Zhao, P.; Zhuo, R.; Li, S.; Lin, H. Experimental Research on the Properties of "Solid-Gas" Coupling Physical Simulation Similar Materials and Testing by Computer of Gas in Coal Rock. Wirel. Pers. Commun. 2017, 102, 1539-1556. [CrossRef]

21. Kong, X.; Wang, E.; He, X.; Zhao, E.; Zhao, C. Mechanical characteristics and dynamic damage evolution mechanism of coal samples in compressive loading experiments. EnFM 2019, 210, 160-169. [CrossRef]

22. Warguła, Ł.; Wojtkowiak, D.; Kukla, M.; Talaśka, K. Symmetric Nature of Stress Distribution in the Elastic-Plastic Range of Pinus L. Pine Wood Samples Determined Experimentally and Using the Finite Element Method (FEM). Symmetry 2020, 13, 39. [CrossRef]

23. Mou, Y.; Zhou, C.; Jiang, N.; Xiao, W.; Du, C.; Meng, X. Experiment Study on Proportioning of Similar Materials in Weak Surrounding Rocks of Rich-Water Faults. Geotech. Geol. Eng. 2020, 38, 3415-3433. [CrossRef]

24. Krawiec, P. Analysis of selected dynamic features of a two-wheeled transmission system. J. Theor. Appl. Mech. 2017, 55, 461-467. [CrossRef]

25. Krawiec, P.; Rozanski, L.; Czarnecka-Komorowska, D.; Wargula, L. Evaluation of the Thermal Stability and Surface Characteristics of Thermoplastic Polyurethane V-Belt. Materials 2020, 13, 1502. [CrossRef] 